\title{
Soft-shelled turtles (Trionychidae) from the Bissekty Formation (Upper Cretaceous: Turonian) of Uzbekistan: Skull-based taxa and probable skull-shell associations
}

\author{
Natasha S. Vitek ${ }^{\mathrm{a}, *}$, Igor G. Danilov ${ }^{\mathrm{b}}$ \\ a Jackson School of Geosciences, The University of Texas at Austin, 1 University Station C1100, Austin, TX 78712, USA \\ ${ }^{\mathrm{b}}$ Zoological Institute of the Russian Academy of Sciences, Universitetskaya Emb. 1, 199034 St. Petersburg, Russia
}

\section{A R T I C L E I N F O}

\section{Article history:}

Received 11 December 2012

Accepted in revised form 21 February 2013

Available online 30 March 2013

\section{Keywords:}

Testudines

Turtles

Trionychidae

Uzbekistan

Turonian

\begin{abstract}
A B S T R A C T
In this paper we describe previously unpublished trionychid turtle material, consisting of skull fragments, from the Late Cretaceous (late Turonian) Bissekty Formation of the Dzharakuduk locality in Uzbekistan. This material is assigned to two taxa: the skull-based Khunnuchelys kizylkumensis Brinkman et al. (1993, Can. J. Earth Sci. 30, 2214-2223) and Trionychini indet. Two specimens which cannot be confidently attributed to these two taxa are considered Trionychidae indet. In addition to these trionychid taxa known from skulls, the Dzharakuduk turtle assemblage includes at least two shell-based taxa, Aspideretoides cf. A. riabinini and "Trionyx" cf. "T." kansaiensis. For this and other Late Cretaceous localities of Middle Asia and Kazakhstan, we suggest the probable skull-shell associations of Khunnuchelys spp. with "Trionyx" kansaiensis-like forms and Trionychini indet. with Aspideretoides-like forms.
\end{abstract} (C) 2013 Elsevier Ltd. All rights reserved.

\section{Introduction}

Trionychidae Gray, 1825, or soft-shelled turtles, are a clade of aquatic cryptodires (Meylan, 1987). Although their remains are abundant in the fossil record, many specimens are indeterminate fragments and many taxa are based entirely on either skulls only or shells only (Hutchison, 2000). This is especially true for Cretaceous trionychids, which are important for understanding the early diversification and evolution of the family (see Danilov and Vitek, 2012 for a review of Cretaceous trionychids of Asia).

This paper continues a series of publications on Cretaceous trionychids of Asia (Danilov and Vitek, 2009; Vitek and Danilov, 2010, 2012; Danilov and Vitek, 2012, 2013) and is devoted to skull-based trionychids from the Late Cretaceous (late Turonian) Bissekty Formation of the Dzharakuduk (Dzharakuduk II; Nessov, 1997) locality in Uzbekistan. Although a much more in-depth review was published recently (Danilov and Vitek, 2012), it is important to note that the Dzharakuduk locality is important in terms of the large sample of trionychid fossils collected and in terms of the presence of both skull fragments and shell fragments of trionychids. Below, the skull-based material is assigned to two skull-based taxa: Khunnuchelys kizylkumensis Brinkman et al., 1993 and Trionychini

\footnotetext{
* Corresponding author.

E-mail addresses: nsvitek@utexas.edu (N.S. Vitek), igordanilov72@gmail.com (I.G. Danilov).
}

indet. One specimen which cannot be confidently attributed to these two taxa is considered Trionychidae indet. In addition, we discuss probable skull-shell associations among Cretaceous trionychids of Dzharakuduk and other Late Cretaceous localities of Middle Asia and Kazakhstan. Our previous publication (Danilov and Vitek, 2013) examined shell-based taxa from this locality and briefly described the previous studies of Dzharakuduk trionychids.

The material for this study, as well as for our previous study (Danilov and Vitek, 2013), was collected by L.A. Nessov between 1977 and 1994 and by the international Uzbek/Russian/British/ American/Canadian Joint Paleontological Expeditions (URBAC) led by J.D. Archibald between 1997 and 2006.

Institutional abbreviations-CCMGE, Chernyshev's Central Museum of Geological Exploration, St. Petersburg, Russia; UMMZ, University of Michigan Museum of Zoology, Ann Arbor, Michigan, USA; ZIN PH, Paleoherpetological collection, Zoological Institute of the Russian Academy of Sciences, St. Petersburg, Russia.

\section{Systematic paleontology}

Testudines Batsch, 1788

Cryptodira Cope, 1868

Trionychia Hummel, 1929

Trionychidae Gray, 1825

Trionychinae Gray, 1825

Khunnuchelys Brinkman, Nessov and Peng, 1993 
Khunnuchelys kizylkumensis Brinkman, Nessov and Peng, 1993

Fig. 1

Trionyx sp.: Nessov, 1986:fig. 14a, b; pl. I, fig. 9.

Cf. Eurycephalochelys: Chkhikvadze and Shuvalov, 1988:199.

Cf. Axestemys riabinini: Kordikova, 1994a:344.

Axestemys (Axestemys) sp.: Kordikova, 1994b:7.

«Trionyx» sp.: Nessov, 1997:pl. 41, fig. 6.

Khunnuchelys kizylkumensis: Brinkman et al., 1993:2216, figs. 4-8; Nessov, 1997:144, 145, pl. 13, fig. 18; Chkhikvadze, 1999:217; Chkhikvadze, 2000:56; Danilov and Parham, 2005:789; Danilov and Vitek, 2009:53; Vitek and Danilov, 2010:391; Danilov and Vitek, 2012:426.

Holotype. CCMGE 8/12458, a braincase and skull roof.

Locality, Horizon, and Age.

Dzharakuduk (=Dzharakuduk II; Nessov, 1997), Central Kizylkum Desert, Navoi Viloyat (district), Uzbekistan; Bissekty Formation, late Turonian.

Previously referred material. CCMGE 303/12458, partial maxilla; CCMGE 8a/12458, braincase.

Newly referred material. ZIN PH 3/17, partial maxilla; ZIN PH 17/17, partial skull roof; ZIN PH 35/17, partial right braincase; ZIN PH 39/ 17, partial left braincase; ZIN PH 38/17, partial left prootic, quadrate, and parietal; ZIN PH 27/17, partial dentary.

Emended diagnosis. As given in Brinkman et al. (1993). In addition, the maxilla contributes to the anteroventral margin of the temporal arch, and both the maxilla and the dentary have triangular, beaklike triturating surfaces.

Description of new material. A partial maxilla (ZIN PH 3/17) is almost identical in its morphology to a previously figured partial maxilla (CCMGE 303/12458; Nessov, 1986, Fig. 14a, b). ZIN PH 3/ 17 preserves part of the orbit margin, part of the triturating surface, and part of the temporal arch (Fig. 1A-D). No part of the jugal remains, but the suture indicates that the maxilla contributed to the anteroventral part of the temporal arch, and contacted the jugal dorsally. The triturating surface is not a separate, flat surface differentiated from the rest of the palate. Instead, the edge of the maxilla is relatively thin and beak-like, and the triturating surface is vaulted and confluent with the rest of the palate.

The skull roof, formed by the parietals and partially by the frontals, is thickened. A fragment (ZIN PH 17/17, Fig. 1E-H), approximately the same size as that of ZIN PH 7/17 (described below), is approximately $8 \mathrm{~mm}$ thick. The comparable specimen (ZIN PH 7/17) is only $4 \mathrm{~mm}$ thick. In dorsal view, small fragments of the parietal or fragmented surfaces where the parietal would have contacted the prootic are visible in ZIN PH 39/17 (Fig. 1I-N), ZIN PH 35/17 (Fig. 10-V) and ZIN PH 38/17 (Fig. 1W-X). In these fragments, the parietal contact with the prootic is anteromedial to the processus trochlearis oticum, precluding the parietal from participating in this process.

In ventral view, the pterygoid contacts the quadrate posterolaterally, the basisphenoid medially, and the palatines anteromedially (Fig. 1M, N, S, T). It fully encloses the foramen posterius canalis carotici interni, although because the basioccipital tubercle is not preserved the position of the foramen in reference to that structure cannot be determined. In lateral view (Fig. $1 \mathrm{~K}, \mathrm{~L}$ ), the pterygoid contacts the quadrate posterodorsally and forms the ventral and posterior margin of the formen nervi trigemini. In posterior view (Fig. $1 \mathrm{U}, \mathrm{V}$ ), the pterygoid contacts the quadrate laterally and forms the ventral margin of the fenestra postotica. Although the fenestra is partially covered by matrix, it does not appear to be divided.

The basisphenoid is only partially preserved in a single specimen (ZIN PH 35/17, Fig. 1S, T). Based on the preserved fragment, it had no noticeable medial restriction and was probably triangular.

A single left exoccipital is partially preserved (ZIN PH 35/17, Fig. 1Q R). The exoccipital forms the lateral wall of the foramen magnum. In posterior view, it contacts the supraoccipital dorsally and the opisthotic dorsolaterally. Potential contact with the pterygoid is obscured by matrix, and no part of the basioccipital or suture with the basioccipital is preserved. The ventral region, where the hypoglossal foramina would be found, also is not preserved.

Less than half of the supraoccipital is preserved in a single specimen (ZIN PH 35/17, Fig. 10-R). In dorsal view, it contacts the parietal anteriorly, the prootic anterolaterally, and the opisthotic laterally. The crista supraoccipitalis is missing. In posterior view, the supraoccipital contacts the opisthotic ventrolaterally and the exoccipital ventrally. With the opisthotic, it forms a large, rounded dorsal ridge that separates the dorsal surface from the posterior surface of the skull, as was described previously in other specimens of Khunnuchelys (Brinkman et al., 1993). Unlike Khunnuchelys erinhotensis, the supraoccipital has no spinelike process that extends into the opisthotic.

In ventral view, the opisthotic makes up much of the abovementioned rounded ridge. Ventral to the ridge, dorsal to the fenestra posotica, and lateral to the foramen magnum is a roughly circular concave surface (Fig. 1Q, R). The opisthotic has no descending process that would subdivide the fenestra postotica, unlike Khunnuchelys erinhotensis. The opisthotic contacts the supraoccipital dorsomedially, the exoccipital ventromedially, and the quadrate laterally. In dorsal view, the opisthotic contacts the quadrate anterolaterally, the prootic laterally, and the supraoccipital anteromedially.

The quadrate completely encloses the incisura columella auris (Fig. 1K, L, U, V) within the cavum tympanum. A sharp, welldeveloped ridge extends from the incisura columella auris, but its direction within the cavum tympanum is not consistent. The quadrate does not contribute to the margin of the foramen nervi trigemini. In dorsal view, the quadrate is partially covered by the squamosal laterally, contacts the opisthotic posteromedially, and the prootic medially (Fig. 10, P). In ventral view, the quadrate contacts the pterygoid medially and the prootic anteromedially. In posterior view, the quadrate contacts the opisthotic dorsomedially and the pterygoid ventromedially.

In dorsal view (Fig. 1I, J, O, P, W, X), the prootic is shorter and wider than the prootic seen in most other trionychids (see, for example, the trionychine prootic described below). The suture between the quadrate and the prootic, on which lies the foramen stapedio-temporale, is not perpendicular to the processus trochlearis oticum. The prootic contacts the quadrate laterally, the opisthotic posteriorly, the supraoccipital posteromedially, and the parietal anteromedially. The anterior margin of the prootic is bent (Fig. 1I, J, W, X), unlike the relatively straight margin of most other trionychids. The processus trochlearis oticum occurs only on the lateral arm of this margin. It is made up at least partially by the prootic and the quadrate. The medial arm is thinner and smoother, and made up by the prootic and parietal. A fragment preserving much of the processus trochlearis oticum (ZIN PH 38/17, Fig. 1W, X) is large. Its size is similar to a comparable part of a large specimen of Khunnuchelys sp. from the Bostobe Formation (Khunnuchelys sp. 1; Danilov and Vitek, 2012), indicating that individuals in the two 

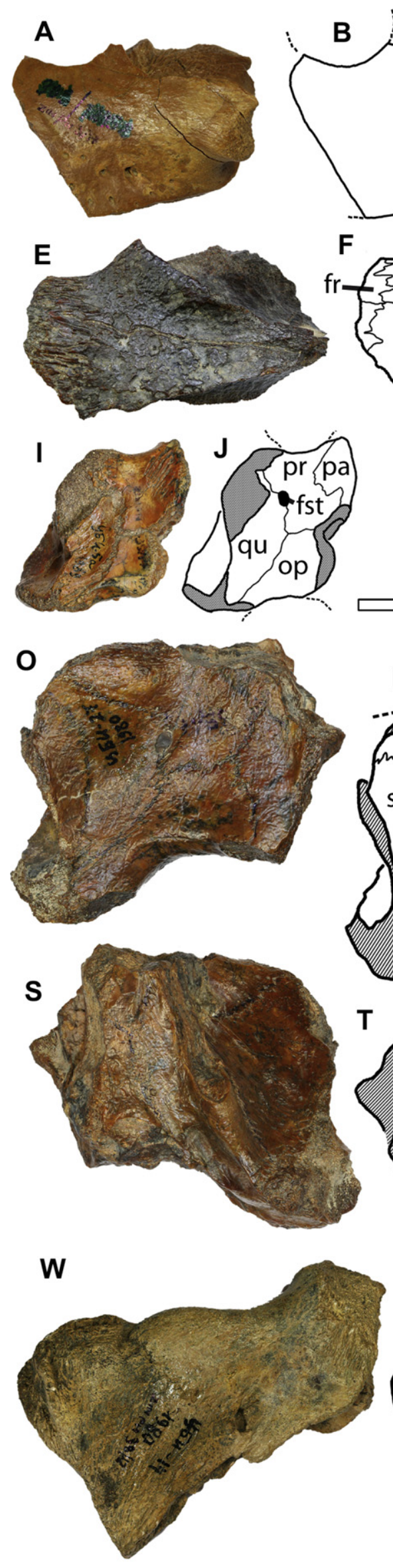
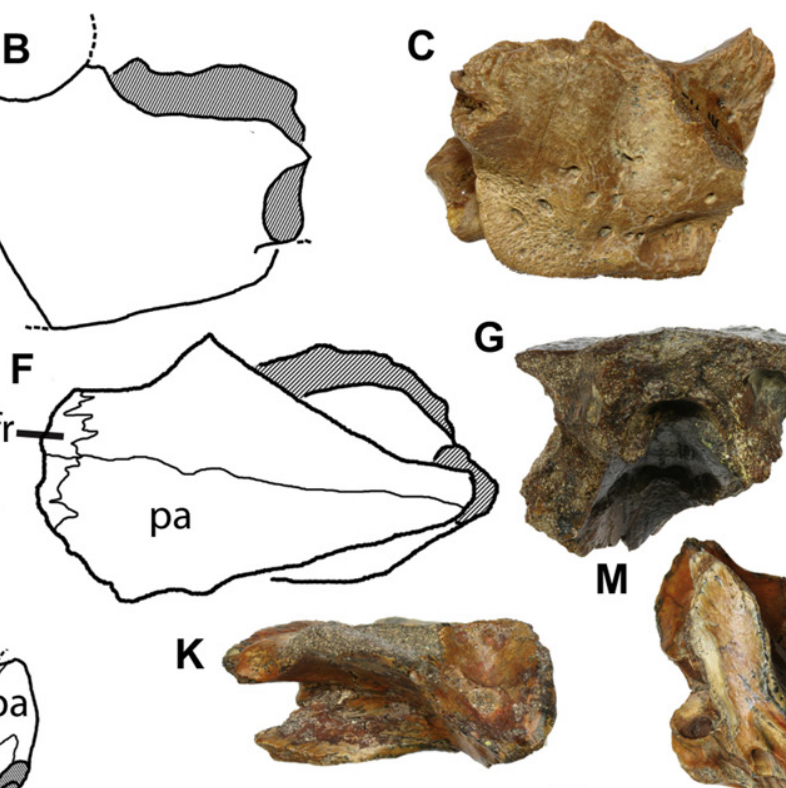

$5 \mathrm{~cm}$

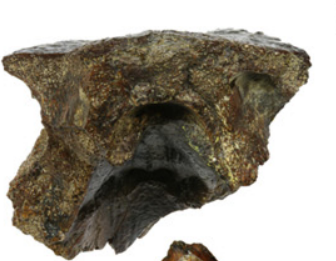

$\mathbf{M}$
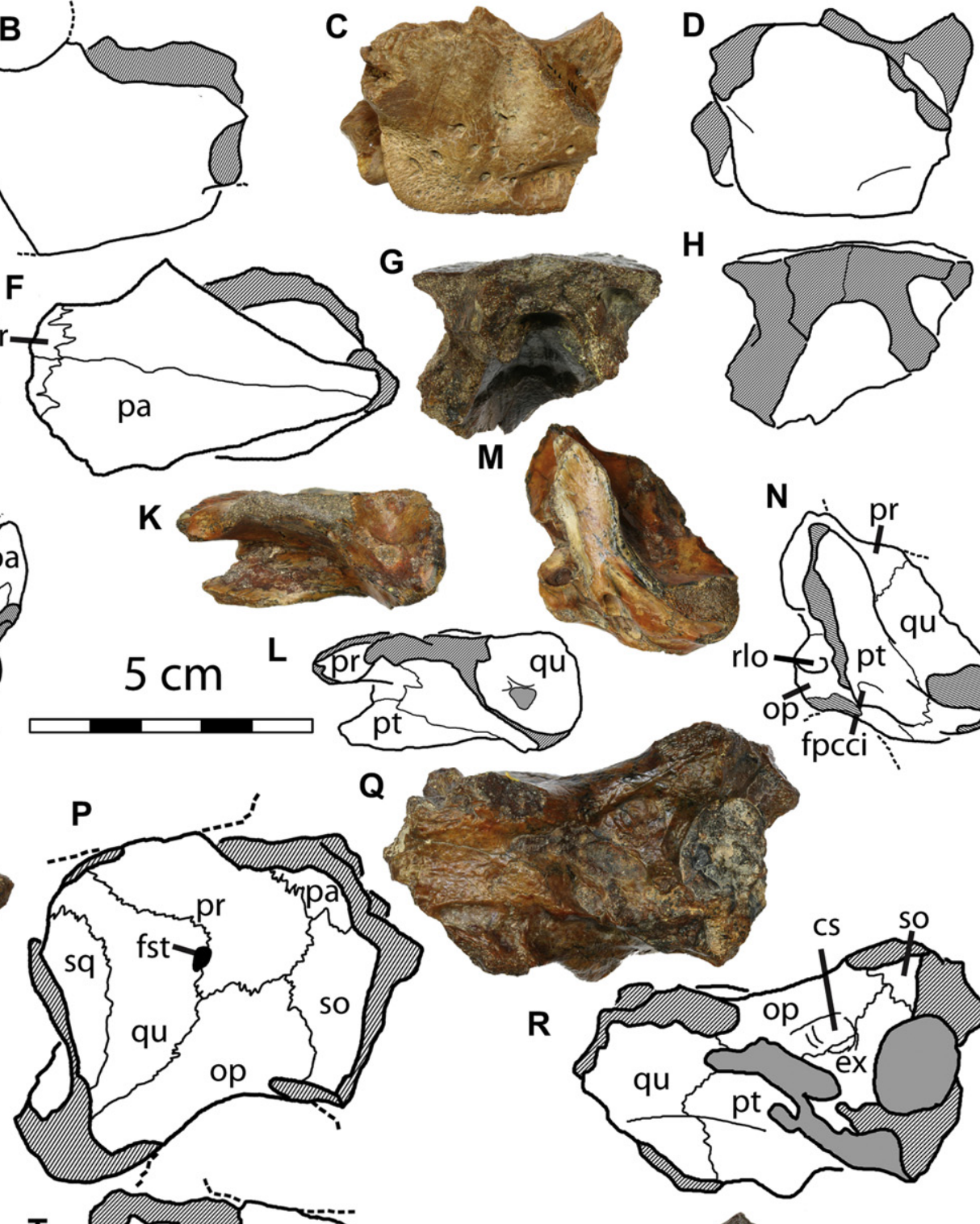

H
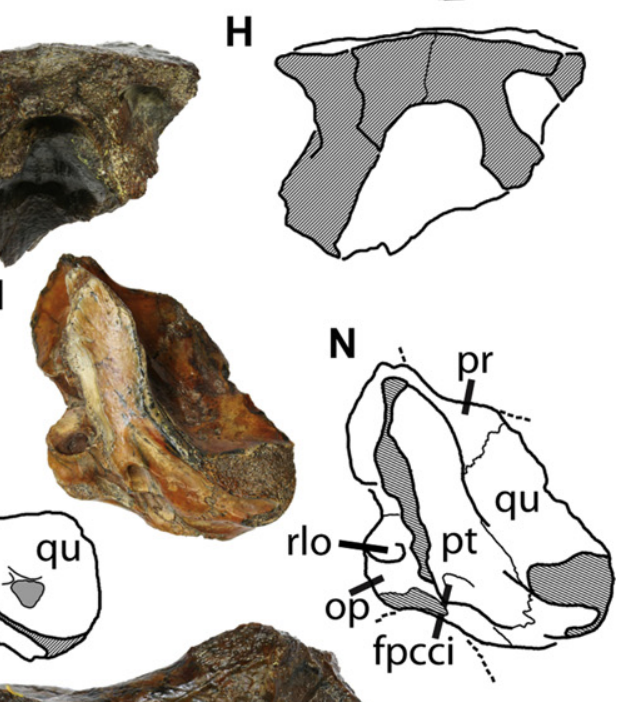

R
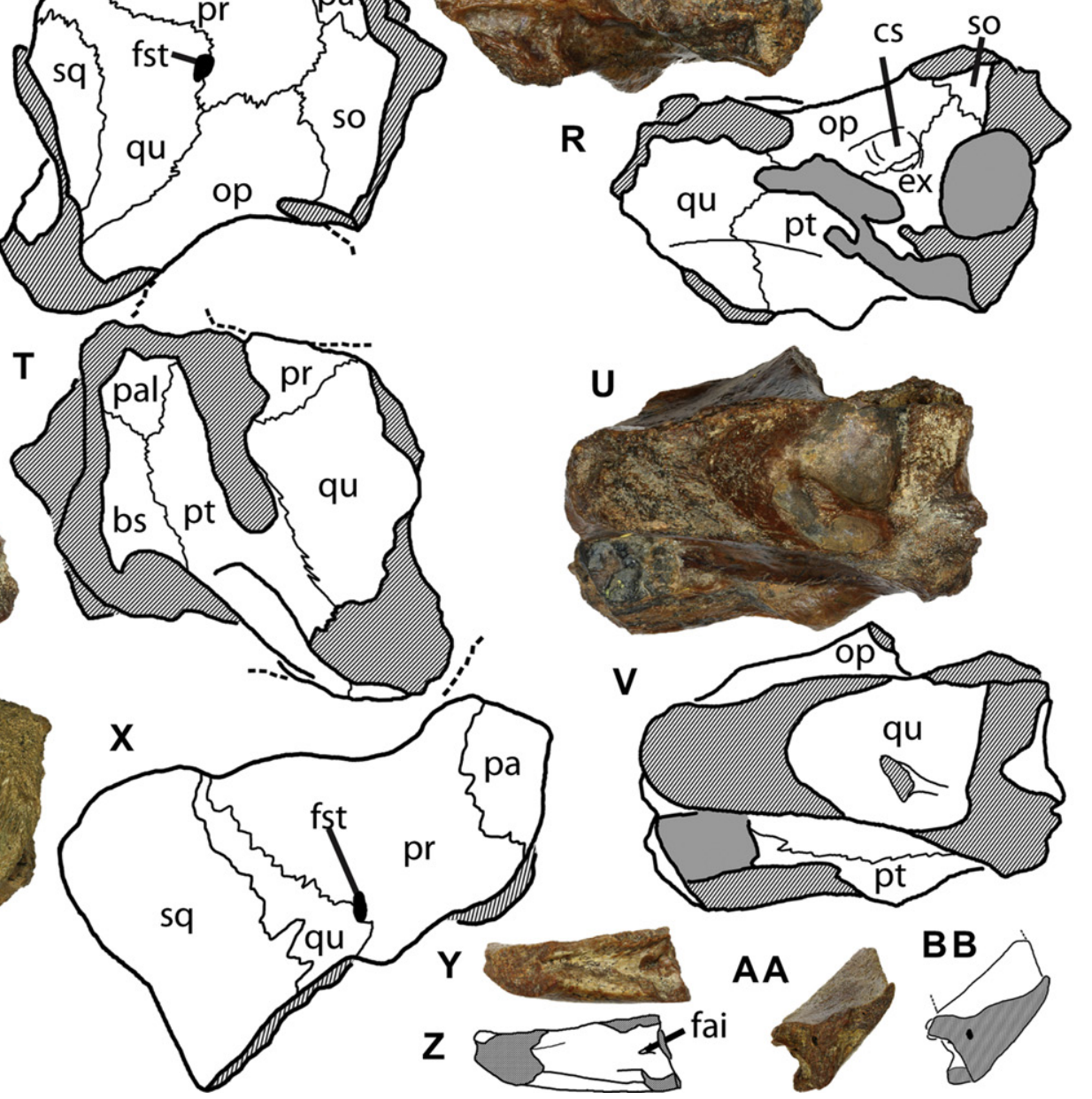

BB

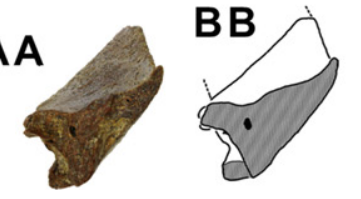


different localities reached similar sizes (about $20 \mathrm{~cm}$ in skull length).

The only preserved portion of the mandible is best interpreted as a partial dentary (ZIN PH 27/17, Fig. 1Y-BB). It is composed of a single bone with a shallow groove along one side. The side with the groove and the opposite side are complete, but the two opposing, triangular sides are broken surfaces. Because the fragment only consists of one bone, the groove is not the fossa Meckelli, which is composed of multiple bones. The groove is similar to broader, shallower grooves found on the medial surface of dentaries of other trionychids, and therefore the foramen within the groove is best interpreted as the foramen alveolare inferious. The triturating surface of the dentary is wide and smooth. The proportions of the triturating surface in comparison to the other bone surfaces suggests that the lower jaw was also beak-like, similar to the maxilla.

Remarks. The material can be identified as belonging to Khunnuchelys based on its similarity with the previously published material of Khunnuchelys in shape of the triturating surface and the deep suborbital region of the maxilla, the thick skull roof, the shape of the anterior margin of the parietal and prootic, the exclusion of the parietal from the processus trochlearis oticum, and the large size of several fragments (Brinkman et al., 1993). The presence of an undivided fenestra postotica diagnoses these specimens specifically as K. kizylkumensis. The material described here provides new characters for $K$. kizylkumensis, including the beak-like ventral maxillary margin, the contribution of the maxilla to the temporal arch, and the unusual dimensions of the dentary. In addition, the new material shows that the skulls of $K$. kizylkumensis could reach relatively large sizes, at least $20 \mathrm{~cm}$ in length.

Trionychini indet.

Figs. 2-4

Trionyx sp.: Nessov, 1987:pl. II, fig. 8.

"trionychid with slender jaws": Brinkman et al., 1993:2218.

"Trionyx" sp.: Nessov, 1997:pl. 40, fig. 2.

?Khunnuchelys sp.: Nessov, 1997:pl. 41, fig. 7.

Trionychini indet.: Danilov, 2007:66A

Aspideretoides sp.: Danilov and Vitek, 2009, p. 54; 2012:423.

Locality, Horizon, and Age.

Dzharakuduk (=Dzharakuduk II; Nessov, 1997), Central Kizylkum Desert, Navoi Viloyat (district), Uzbekistan; Bissekty Formation, late Turonian.

Referred material. ZIN PH 33/17, ZIN PH 18/17, partial braincases; ZIN PH 20/17, ZIN PH 25/17, partial maxillae and jugals; ZIN $\mathrm{PH} 7 / 17$, partial skull roof; ZIN PH 29/17, ZIN PH 31/17, partial dentaries.

Description. Most of the braincase is preserved in ZIN PH 33/17 (Fig. 2) and ZIN PH 18/17 (Fig. 3), including a partial endocast of the brain in ZIN PH 33/17 (Fig. 2A, B). No squamosals, supraoccipital crests, or occipital condyles are preserved, although the squamosal contact with the quadrate is preserved in multiple specimens. Other bones are partially preserved as skull fragments.

ZIN PH 20/17 (Fig. 4A-D) preserves part of the margin of the external nares, as well as part of the orbit margin. Based on this fragment as well as ZIN PH 25/17 (Fig. 4E-H), the snout was longer and shallower than that of Khunnuchelys spp., but not as elongated as in Aspideretoides foveatus or in North American plastomenids (Gardner et al., 1995; Joyce and Lyson, 2011). The triturating surface is separate from the rest of the palate, like almost all other known trionychids with the notable exception of Khunnuchelys spp. Smaller, presumably younger, individuals may have tooth-like serrations on the lateral edge of the triturating surface (Fig. 4E, F). Just dorsal to the posterior end of the triturating surface, the jugal contacts the maxilla. Both the jugal and the maxilla contribute to the margin of the orbit. Unlike Khunnuchelys spp., the maxilla does not contribute to the temporal arch.

The parietal of ZIN PH 18/17 (Fig. 3A, B), as well as the isolated parietal ZIN PH 7/17 (Fig. 4I-L) contacts the frontals anteriorly. It is unclear whether, like in plastomenids, the parietal contributed to the wall of the orbit because the anterolateral margin of each specimen is broken. The thickness of the bone at the contact between the two frontals and two parietals is approximately $4 \mathrm{~mm}$, in contrast to the skull roof of Khunnuchelys kizylkumensis from the same locality. Within the upper temporal fossa, the anterior margin of the parietal and prootic, including the area of the processus trochlearis oticum, is relatively straight, unlike the bent margin seen in Khunnuchelys spp. It is not possible to estimate accurately the amount of parietal contribution to the processus trochlearis oticum. The anterior margin of the parietal is missing in the larger braincase. In the smaller braincase (ZIN PH 18/17) much of that anterior margin is incompletely preserved. In both braincases any potential contribution from the quadratojugal that could be used to calculate total process length is missing. However, it is clear from the anteromedial margin of the prootic that the parietal contributed to the processus trochlearis oticum to some extent, unlike Khunnuchelys spp.

In ventral view (Fig. 3C, D), the palatines contact the pterygoids posterolaterally and the basisphenoid posteromedially. The parts of the palatines that are preserved are flat, without any Khunnuchelyslike grooves. The foramen palatinum posterius is not visible on either palatine, although they may have been located more laterally on parts of the palatines that are not preserved. In lateral view (Fig. 3E, F), the palatines have an ascending process that meets the parietals anteriorly.

In ventral view, the pterygoids contact the palatines anteriorly, the basisphenoid and basioccipital medially, and the quadrates laterally (Fig. 3C, D). Posteriorly, the pterygoids form part of the ventral margin of the skull. In posterior view of the larger braincase, (ZIN PH 33/17, Fig. 2E, F), they and the exoccipitals form a small tubercle that extends dorsally but does not contact a similar tubercle descending from the opisthotic and exoccipitals (see below). In the smaller braincase, no such tubercle is present (Fig. 3G, H). The pterygoids contact the exoccipitals and basioccipital medially and the quadrates laterally. Each pterygoid completely surrounds a

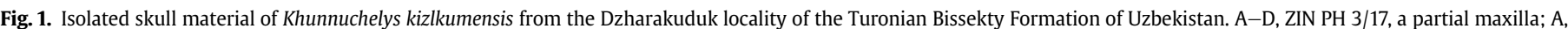

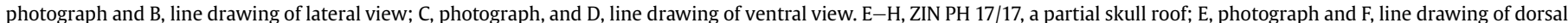

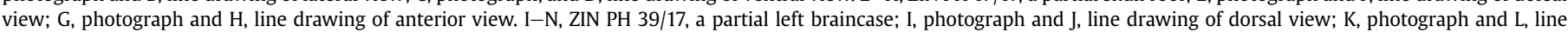

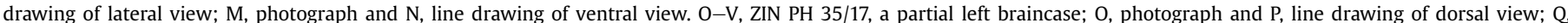

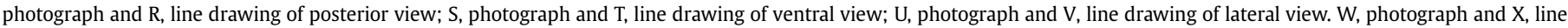

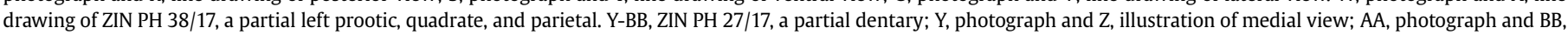

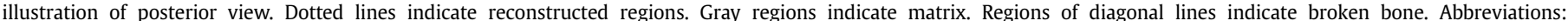

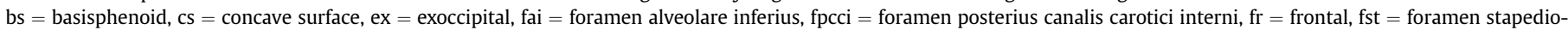

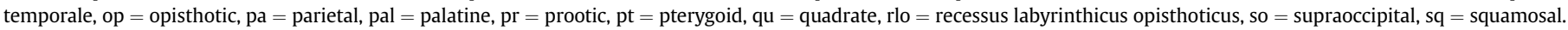



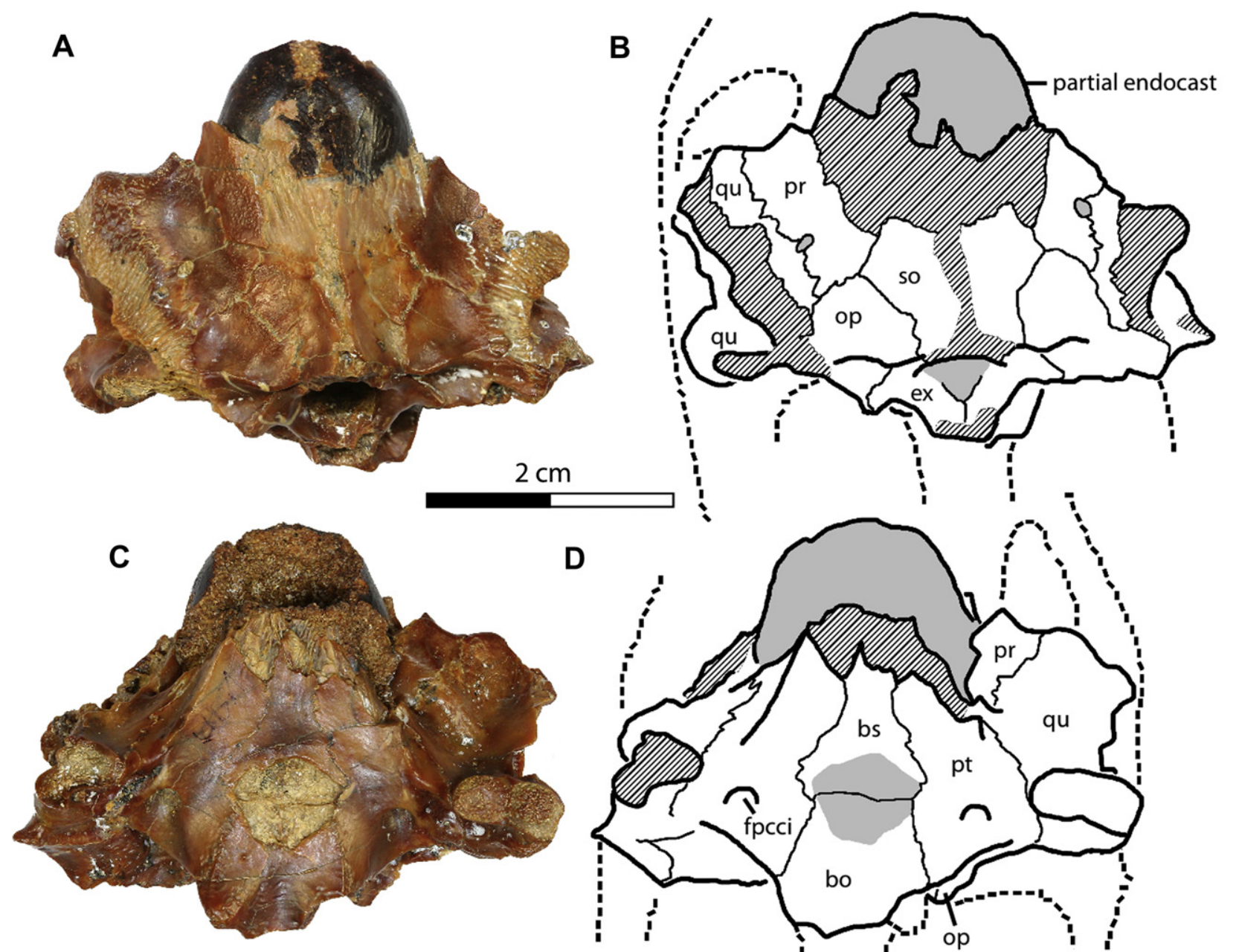

D
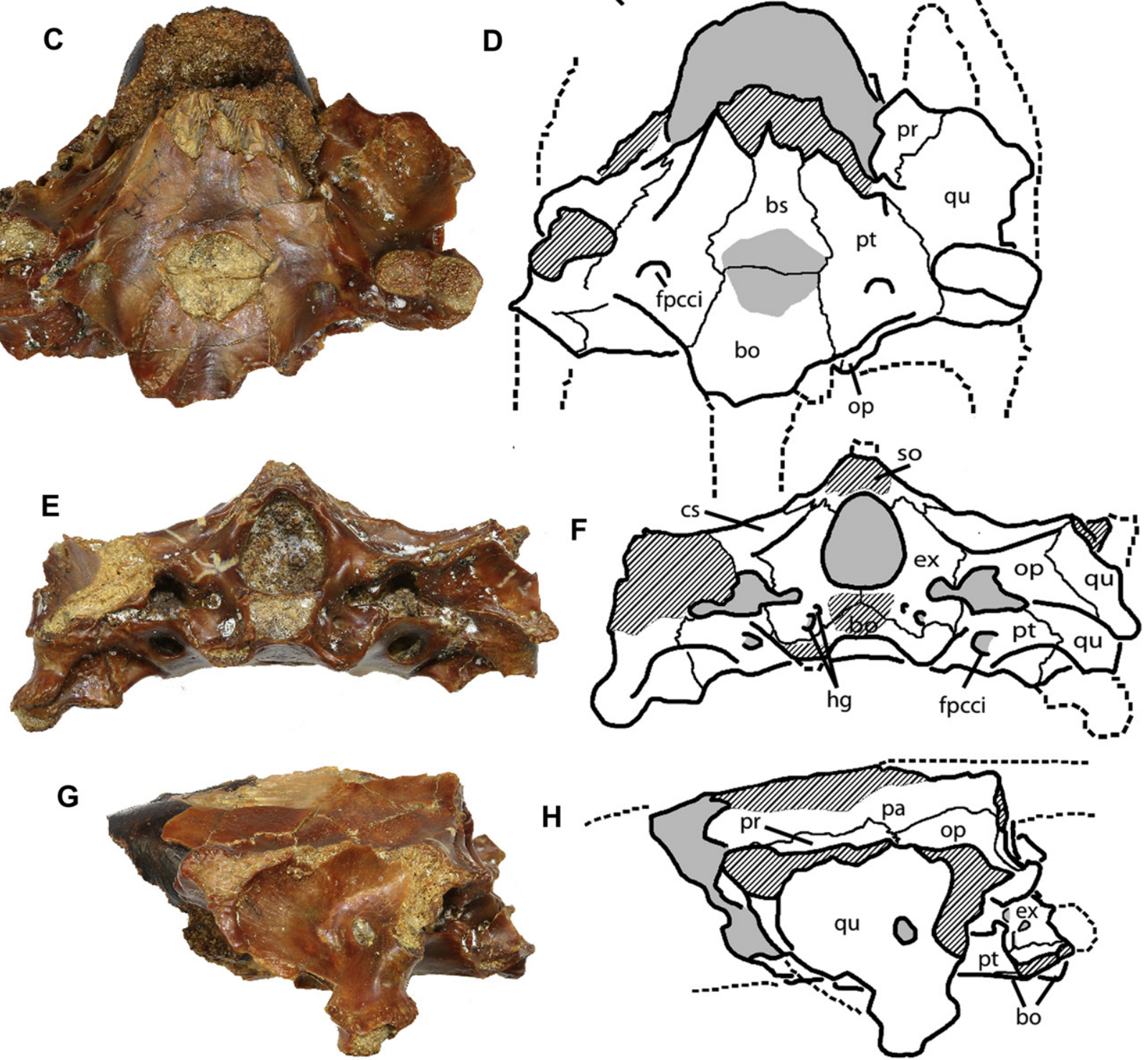

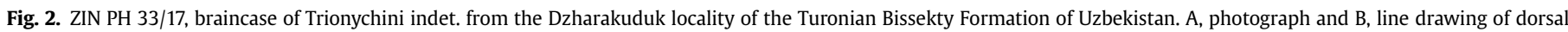

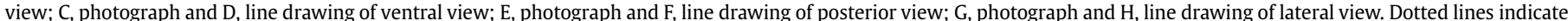

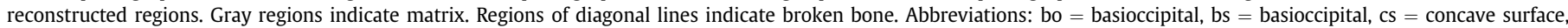

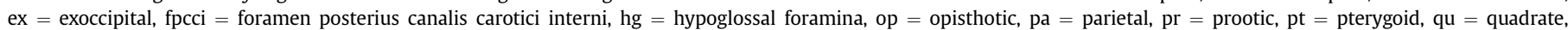
so $=$ supraoccipital. 
foramen posterius canalis carotici interni. Those foramina are located below the basioccipital tubercle, in contrast to Campanian specimens of Axestemys splendida Hay, 1908, in which the foramen posterius canalis carotici interni are located within the tubercle (Gardner, 1992; Gardner et al., 1995).

Although part of the basisphenoid is missing in the larger braincase (ZIN PH 33/17), the location of its contacts is preserved in the smaller braincase (ZIN PH 33/17, Fig. 3C, D). It contacts the pterygoids laterally and the basioccipital posteriorly, as in other trionychids. There is a noticeable constriction along the length of the smaller braincase (Fig. 3C, D), but the condition in the larger braincase is unclear.

The occipital condyles are missing in both braincases. However, it is clear from the surface of exposed bone in the larger braincase (ZIN PH 33/17) that the basioccipital made up the lower third of the element (Fig. 2E, F). In posterior view, the basioccipital contacts the exoccipitals dorsally, and because of this contact does not contribute to the foramen magnum. Laterally, it briefly contacts the pterygoids. In ventral view (Figs. 2C, D, 3C, D), the basioccipital contacts the basisphenoid anteriorly and the pterygoids laterally.

The exoccipitals frame the foramen magnum laterally and ventrally (Figs. 2E, F, 3G, H). In posterior view, they contact the supraoccipital dorsally, the opisthotics dorsolaterally, the pterygoids ventrolaterally, and the basioccipital ventrally along the dorsal surface of the basioccipital turbercle. Dorsally, both the exoccipital and opisthotic participate in a process that descends ventrally toward the pterygoid. However, that process and the pterygoid do not meet. The contribution of both bones to such a process is similar to that of Gilmoremys lancensis Gilmore, 1928 from the Late Cretaceous of North America (Joyce and Lyson, 2011). Ventrally, a similar process that ascends dorsally is formed mainly by the exoccipital with a small contribution from the pterygoid in the larger braincase. Each exoccipital has two hypoglossal foramina in the larger skull. Only one hypoglossal foramen in total is visible on the smaller braincase, but that region of the skull is incompletely preserved.

The crista supraoccipitalis is not preserved. In posterior view (Figs. 2E, F, 3G, H), the supraoccipital forms the dorsal margin of the foramen magnum and contacts the exoccipitals ventrally. In dorsal view (Figs. 2A, B, 3A, B), the supraoccipital contacts the parietals anteriorly, the prootics anterolaterally and the opisthotic posterolaterally.

In dorsal view (Figs. 2A, B, 3A, B), the opisthotic contacts the quadrate laterally, the prootic anteriorly, the supraoccipital anteromedially, and the exocccipital posteromedially. In posterior view (Figs. 2E, F, 3G, H), the opisthotic contacts the quadrate laterally and the exoccipital medially. The opisthotic does not completely subdivide the fenestra postotica (see above). The supraoccipital and opisthotic do not form a rounded ridge that clearly forms a boundary between the posterior and dorsal surfaces, like the ridge present in Khunnuchelys spp. (Brinkman et al., 1993). However, the supraoccipital and opisthotic do form a small, relatively sharp ridge anterior to the posterior surface of the fossil (Fig. 2E, F). The formation of this ridge also produces a small, concave surface above the fenestra postotica and lateral to the foramen magnum. The smaller braincase (ZIN PH 18/17) also has a ridge and a concave surface, but the ridge is even less pronounced and more anteriorly positioned (Fig. 3G, H).

The quadrate entirely encloses the incisura columella auris (Figs. 2G, H, 3E, F). In the cavum tympanum, a low ridge partially encircles the incisura columella auris. The quadrate makes up part of the foramen nervi trigemini in both braincases. The prootic contributes to the dorsal margin of the foramen. Which bones contribute to the rest of the margin is unclear, although a fragment of what is probably the epipterygoid is visible along the dorsal margin of the right foramen nervi trigemini in the larger braincase. In dorsal view (Figs. 2A, B, 3A, B), the quadrate contacts the prootic anteromedially and the opisthotic posteromedially. On the larger braincase, a broken region indicates a contact with the squamosal that would have covered the lateral part of the quadrate and the cavum tympanum.

In dorsal view, the prootic is relatively rectangular in form, as opposed to the more triangular shape of the prootic in specimens of Khunnuchelys spp. It makes up a majority of the processus trochlearis oticum in comparison to the variably preserved quadrate and parietal, but in no specimen is the entire process preserved (Figs. 2A, B, 3A, B). Therefore, estimating the proportion of contribution of different bones is not possible (see above). The prootic contacts the quadrate laterally, the parietal anteromedially, the supraoccipital posteromedially, and the opisthotic posteriorly. The suture with the quadrate is relatively straight and perpendicular to the processus trochlearis oticum. The foramen stapedio-temporale is located within the suture between the quadrate and the prootic. In ventral view, the prootic contacts the parietal anteriorly and the quadrate posteriorly.

The only remains of the mandible are partial dentaries (ZIN PH 29/17 Fig. 4M-P; ZIN PH 31/17, Fig. 4Q-V). The smaller dentary preserves the anterior part of the coronoid process, which is not as steeply angled as that in Gilmoremys lancensis, and therefore probably not as high when it was complete (ZIN PH 29/17, Fig. 4M, $\mathrm{N})$. The specimen also preserves a shallow dentary pocket, similar to that seen in Aspideretoides foveatus Leidy, 1856 (Fig. 40, P; Gardner et al., 1995). The larger dentary preserves a low, rounded pair of ridges at the dentary symphysis (Fig. $4 \mathrm{Q}, \mathrm{R}$ ). The ridges are not similar to the single, high symphyseal ridge found in Aspideretes Hay, 1904 (Meylan, 1987).

Remarks. The unique character combination of basisphenoid-palatine contact. position of the foramen posterius canalis carotici interni completely within pterygoid, closed incisura columella auris, the anterior limit of cheek emargination formed by the jugal, the lack of a visible groove for the stapedial artery on the prootic and parietal, and the limited contribution of the quadrate to the processus trochlearis oticum, diagnose these specimens as belonging to Trionychidae. The shape of the prootic and maxilla, the lack of a maxillary contribution to the temporal arch, the lack of parietal contribution to the processus trochlearis oticum, the lack of palatal grooves, the thinness of the skull roof as seen in the parietals, the contribution of the jugal to the orbital margin, and the smaller size of the preserved elements all indicate that this taxon is distinct from Khunnuchelys. Prior to its description, the specimens were provisionally referred to as Aspideretoides sp. (Danilov and Vitek, 2009, 2012). However, no skull characters were ever provided to diagnose that clade. Only two species with preserved skull material have ever been referred to Aspideretoides. One, Axestemys splendida (formerly Aspideretoides splendidus), differs from the material described above in its larger size, position of the foramen posterius canalis carotici interni, and in the shape of the basisphenoid (Gardner et al., 1995; Vitek, 2012). In comparison to the other species, Aspideretoides foveatus, the material described above is similar in its shallow dentary pocket and general skull shape (Gardner et al., 1995). There are no clear differences between the two skulls, but important characters for either taxon, including the shape of the dorsal margin of the external nares, the shape of the basisphenoid, and the position of the foramen posterius canalis carotici interni, are unknown in one or both species and prevent full comparison.

The confluent fenestra postotica and foramen jugulare posterius, as well as the lack of an extensive secondary palate indicate that the material does not represent a taxon of Cyclanorbinae 


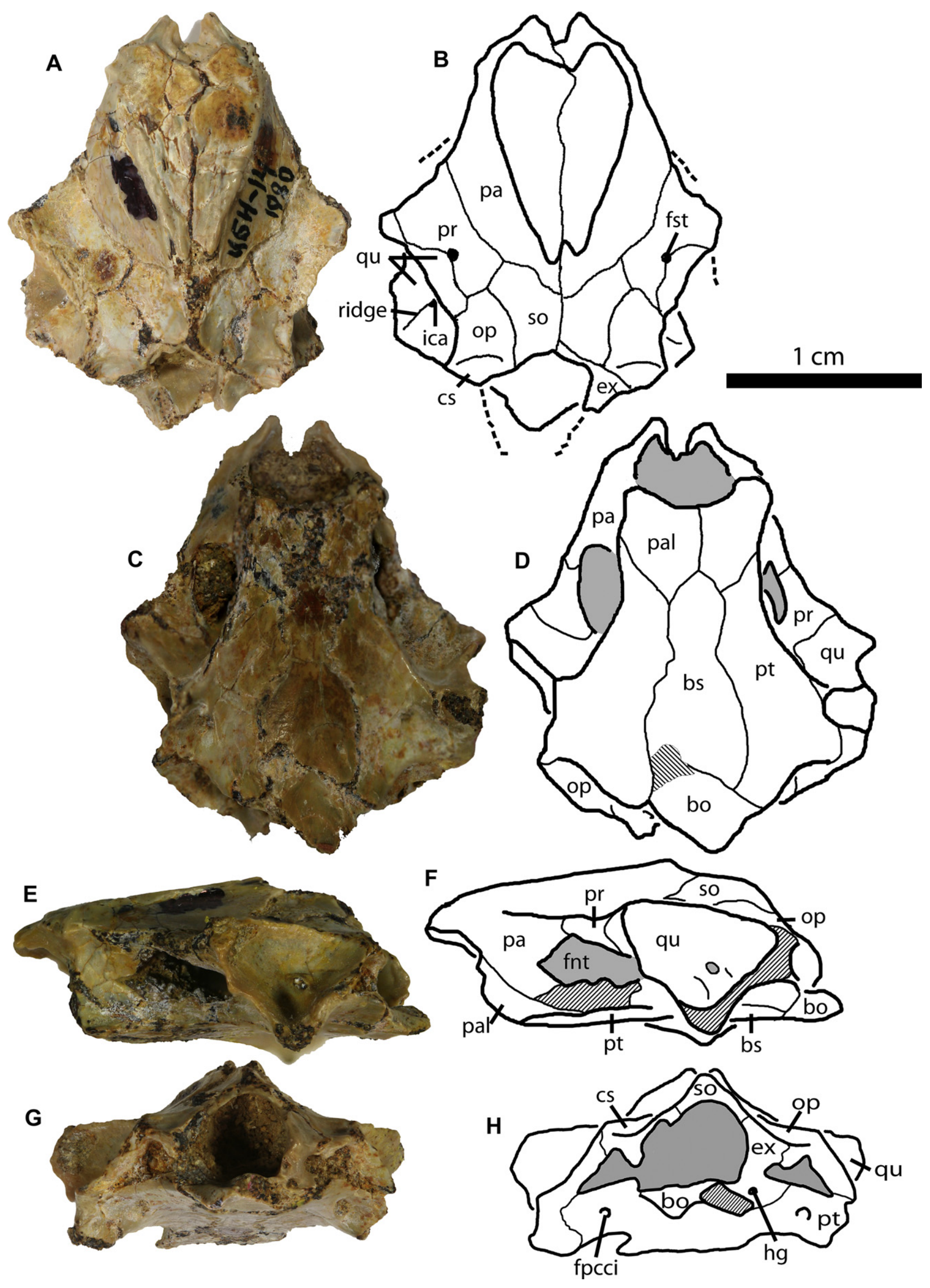


Hummel, 1929 or Plastomenidae Hay, 1908 (Meylan, 1987; Joyce and Lyson, 2011). In addition, the placement of the foramen posterius canalis carotici interni, the absence of a single, distinct symphyseal ridge, the participation of the quadrate in the foramen nervi trigemini, and contact between the exoccipitals and pterygoid, indicate that the material does not represent a member of Chitrini Gray, 1870, Aspideretini Meylan, 1987, Pelodiscini Meylan, 1987, and Trionychina Fitzinger, 1826 (sensu Meylan, 1987). The material cannot be definitively excluded from Apalonina Meylan, 1987, but neither is it clear whether this material has the large intermaxillary foramina and maxillae divided by the vomer that are apomorphic characters for Apalonina. Given that the material does not have its own apomorphic characters and cannot be clearly assigned to any named clade, we refer the material to Trionychini indet. pending the discovery of additional material.

\section{Discussion}

In the original description of Khunnuchelys, the dorsal occipital ridge and the concave surface below it made up of the opisthotic and supraoccipital were considered important diagnostic characters (Brinkman et al., 1993). Those features are clearly visible in specimens of Khunnuchelys described here and elsewhere (Brinkman et al., 1993; Danilov pers. comm.), but similar structures, especially a concave surface above the fenestra postotica in posterior view, are present in other taxa, including the indeterminate trionychine taxa described above, and variably in Lissemys punctata Lacépède, 1788 (e.g., UMMZ 129396) and Gilmoremys lancensis (Joyce and Lyson, 2011:fig. 2.3).

The highly vaulted palate of $K$. kizylkumensis is unusual for a trionychid taxon. A similar feature in the North American Paleocene taxon Conchochelys admiribalis Hay, 1905, was interpreted as useful for crushing hard-shelled prey items such as mollusks. Although adaptation to a durophagous diet is one possible function of the unusual palate structure, the link between shape and function is not clear. The enlarged, unvaulted triturating surface in Apalaone ferox was also interpreted as a crushing surface (Ernst and Barbour, 1989).

The presence of these similar structures in Khunnuchelys spp. and at least one species of cyclanorbine and plastomenid make a comparison between plastomenids and Khunnuchelys spp. potentially informative. Although both clades display some secondary infolding of the palate, the infolding in Plastomenidae is made up of the maxillae, which almost meet at the midline of the palate. In contrast, the maxillae of Khunnuchelys spp. are not at all infolded, and instead form only a single, vaulted surface in palatal view. The palatines are strongly infolded, and almost meet at the midline to encircle the palatal groove (Danilov, pers. comm.). It is notable that $G$. lancensis has a deep medial groove in the palatines posterior to the secondary palate of the maxillae (Joyce and Lyson, 2011:figs. 3.2, $4.2,5.2)$, which is similar to the characteristic groove of Khunnuchelys spp. Other skull characters of Plastomenidae, such as an elongate snout and the separation of the foramen jugulare posterius from the fenestra postotica, are not present in K. kizylkumensis. However, K. erinhotensis has a process of the opisthotic that separates the foramen jugulare posterius from the fenestra postotica, although further comparison is not possible because a single partial skull is the only known specimen of the species.
Despite the presence of multiple skulls of K. kizylkumensis, the lack of shell material for this taxon (see below) as well as the obscured sutures in the more complete specimens means that only ten out of thirty-seven skull characters useful for phylogenetic analysis can be scored for this taxon. Although highly incomplete taxa occasionally can provide valuable phylogenetic information (Kearney and Clark, 2003), in a preliminary phylogenetic analysis based on all available material of Khunnuchelys kizylkumensis, we were unable to resolve sister relationships between Khunnuchelys and other taxa within Trionychidae. Therefore, although there is no phylogenetic support for any hypothesis of relationships between Khunnuchelys and other trionychids, the preliminary comparison above raises the possibility that Khunnuchelys, although not itself a plastomenid, may be more closely related to plastomenids and cyclanorbines than to trionychines. On the other hand, if Khunnuchelys spp. are associated with forms similar to "Trionyx" kansaiensis, then the evidence potentially linking Khunnuchelys to plastomenids is weak given the lack of shared, derived shell characters common to both "T." kansaiensis and plastomenids.

At least one other specimen of an extinct trionychid has been identified from the Dzharakuduk locality. A basisphenoid was figured in dorsal view by Nessov (1987, pl. II, fig. 9) and identified as Trionyx sp. Its repository is unknown and we did not examine this specimen. No characters that allow attribution of this specimen to one of two trionychid taxa known from Dzharakuduk are observable on the published figure. For this reason, we tentatively consider it as Trionychidae indet.

Other indeterminate fragments, including a fragment of the articular surface of a mandible (Fig. $4 \mathrm{~W}, \mathrm{X}$ ), have also been recovered from Dzharakuduk. In dorsal view of the mandible fragment, the surangular contributes to the fossa Meckelii and makes up just under half of the articular area. In extant Trionychidae and Carettochelys insculpta Ramsay, 1886, the surangular makes up at least half, if not more, of the area articularis mandibularis (Meylan, 1987). Both the medial and lateral sides of the mandible fragment are covered in matrix and glue. Therefore, the number and position of the foramen nervi auriculotemporalis cannot be determined.

For any part of the trionychid skull, only two morphotypes at most are discernable among the fossil material from Dzharakuduk. Although there are a large number of indeterminate fragments that cannot be attributed to one or the other morphotype, there are none that suggest the possibility of a third morphotype. Of the 18 skull specimens, 16 can be identified as one of the two morphotypes, and 2 are indeterminate. Among the shell material of trionychids from the same locality, we cannot discern more than two morphotypes for any one part of the shell, although there is the possibility that a third morphotype is present among indeterminate fragments with extensive callosities covering the external surface of plastral bones (Danilov and Vitek, 2013). Over one thousand shell fragments have been recovered from the locality, but a majority of them are too incomplete to assign to any morphotype. Many of those fragments have nondiagnostic sculpture patterns on the visceral surface, further precluding identification.

One morphotype of both skull and shell material can either be assigned to, or has multiple similarities with, the clade Aspideretoides, which is known from at least one nearly complete skeleton of Aspideretoides foveatus from North America (discussed above). Based on this correspondence, it is probable that the shell material

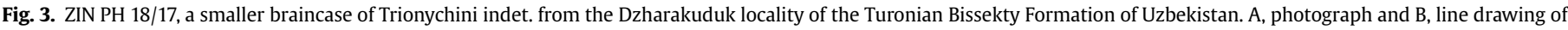

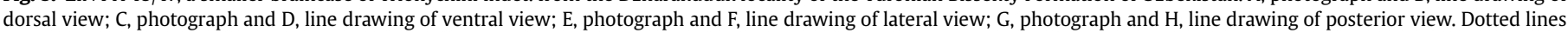

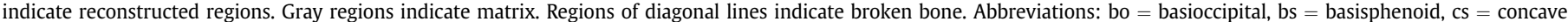

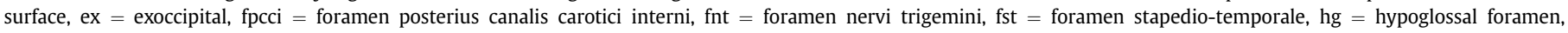
$\mathrm{ica}=$ incisura columella auris, $\mathrm{op}=$ opisthotic, $\mathrm{pa}=$ parietal, $\mathrm{pal}=$ palatine, $\mathrm{pr}=$ prootic, $\mathrm{pt}=$ pterygoid, $\mathrm{qu}=\mathrm{quadrate}, \mathrm{so}=$ supraoccipital . 


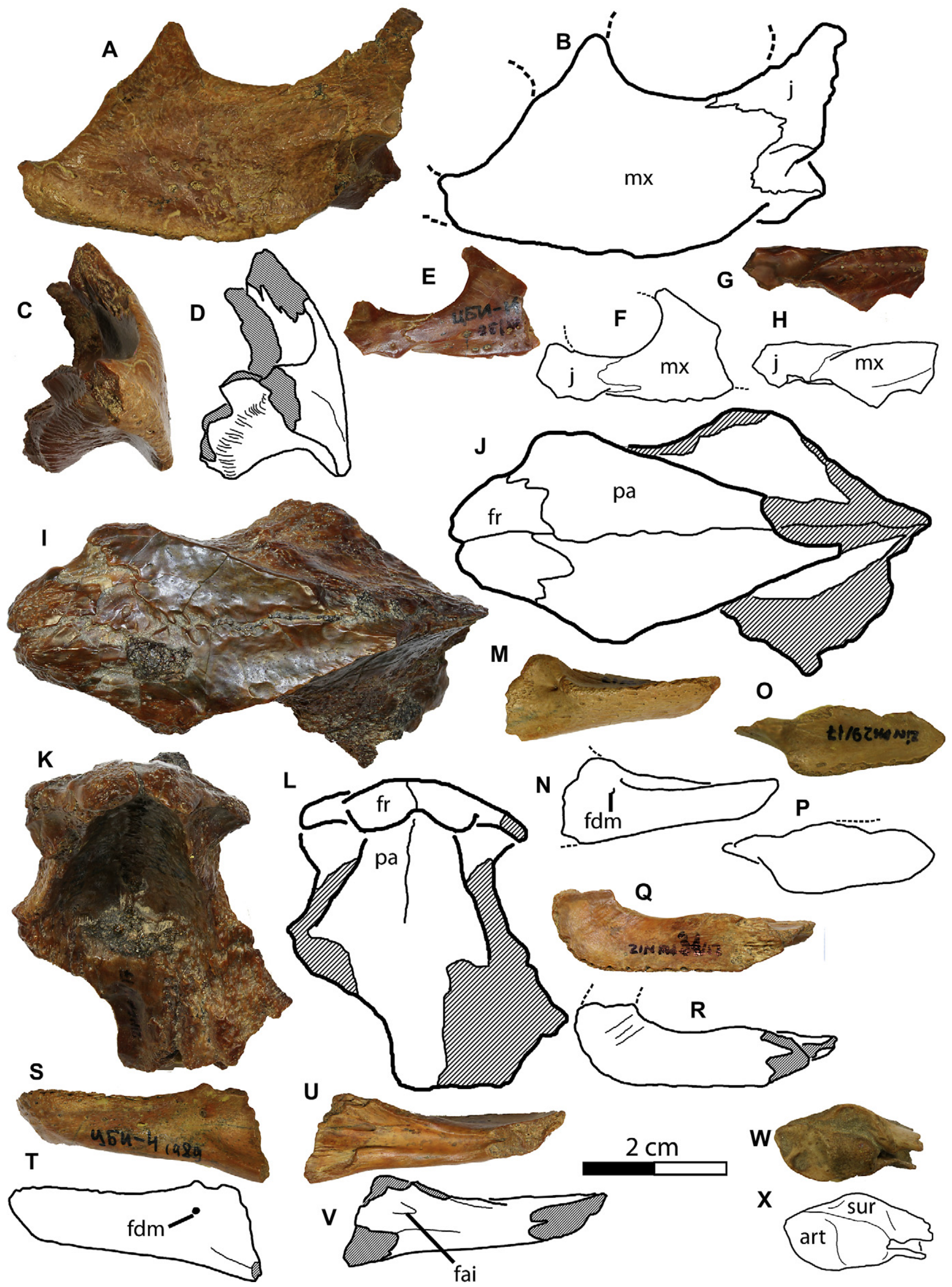


assigned to Aspideretoides cf. riabinini (Danilov and Vitek, 2013) belongs to the same taxon as the skull material described above as Trionychini indet. In addition, the presence of the giant skull-based taxon Khunnuchelys kizylkumensis as well as material either referable to or similar to the giant shell-based taxon "Trionyx" kansaiensis from both this locality and localities in the SantonianCampanian Bostobe Formation (Vitek and Danilov, 2010) is notable. Gigantic size alone is a tenuous character to use for proposing skullshell association, but in both formations only one gigantic species of trionychid is present, and it is most parsimonious to infer that the single giant skull-based taxon and the single giant shell-based taxon probably belong to a single species (Danilov and Vitek, 2009; Vitek and Danilov, 2010). Interestingly, the skull material has a beak-like maxilla and the shell material has a strong anterior emargination reminiscent of other megacephalous turtles, including Platysternon Gray, 1831 as an extreme example (Ernst and Barbour, 1989; Vitek and Danilov, 2010).

However, conclusively linking shell taxa to the skull taxa described above is currently impossible. Although thousands of fragments were collected, no diagnostic skull and shell material from a single individual were discovered in association. The only previously known taxon of Trionychidae from that locality is K. kizylkumensis, itself a skull-only taxon. In addition, the large number of indeterminate fragments leaves open the possibility, however small, that a third taxon was present. Therefore, although we think it is highly likely that the two smaller forms of Trionychini are two parts of a single species and the two giant forms that do not belong within Trionychini are two parts of a single species, we cannot make any formal systematic revisions without the discovery of associated skull-shell material.

\section{Acknowledgments}

Fieldwork for this study, as well as for our previous study (Danilov and Vitek, 2013) was funded by grants from the National Science Foundation (EAR-9804771 and 0207004) and National Geographic Society (5901-97 and 6281-98) to J. D. Archibald and H.-D. Sues, and US Civilian Research and Development Foundation grant RUB1-2860-ST-07 to Alexander Averianov and J. D. Archibald. We thank all members of the URBAC expedition for their help during fieldwork. Laboratory work for this study was funded by a grant from the President of the Russian Federation to the Leading Scientific Schools NSh-6560.2012.4 to I.G.D and by a GSA Graduate Student Research Grant to N.S.V.

\section{References}

Batsch, A.J.G.C., 1788. Versuch einer Anleitung, zur Kenntniss und Geschichte der Thiere und Mineralien (An attempted guidebook to the science and history of animals and minerals). Akademische Buchhandlung, Jena (in German).

Brinkman, D.B., Nessov, L.A., Peng, J.-H., 1993. Khunnuchelys gen. nov., a new trionychid (Testudines: Trionychidae) from the Late Cretaceous of Inner Mongolia and Uzbekistan. Canadian Journal of Earth Sciences 30, 2214-2223.

Chkhikvadze, V.M., 1999. Nekotoriye iskopaemiye trekhkogotniye cherepakhi Azii (Rafetini trib. nov.) (Some fossil soft-shell turtles of Asia (Rafetini trib. nov.)). Trudy Tbilisskogo Gosudarstvennogo Pedagogicheskogo Universiteta 5, 215225 (in Russian).
Chkhikvadze, V.M., 2000. Fossil trionychid turtles from the territory of the Former Soviet Union. In: Chengdu Institute of Biology (Ed.), Fourth Asian Herpetological Conference Programme, Abstracts, Address Book 16-20 July 2000, Chengdu, China. Chinese Academy of Sciences, Chengdu, China, p. 56.

Chkhikvadze, V.M., Shuvalov, V.F., 1988. Novyi vid trioniksa iz verekhnemelovykh otlozheniy Mongolii (A new species of a trionychid from the Upper Cretaceous deposits of Mongolia). Izvestiya Akademii Nauk Gruzinskoi SSR 14, 198-204 (in Russian).

Cope, E.D., 1868. On the origin of genera. Proceedings of the Academy of Natural Sciences of Philadelphia 1868, 242-300.

Danilov, I.G., 2007. New data on soft-shelled turtles (Trionychidae) from the Bissekty Formation (Late Turonian) of Dzharakuduk, Uzbekistan. Journal of Vertebrate Paleontology 27 (Suppl. 3), 66A.

Danilov, I.G., Parham, J.F., 2005. A reassessment of the referral of an isolated skull from the Late Cretaceous of Uzbekistan to the stem-testudinoid turtle genus Lindholmemys. Journal of Vertebrate Paleontology 25, 784-791.

Danilov, I.G., Vitek, N.S., 2009. Cretaceous trionychids of Asia: a review of record and biogeography. In: Brahman, D.R. (Ed.), Turtle Symposium October 17-18, 2009 Abstracts and Program. Special Publication of the Royal Tyrrell Museum, Drumheller, Alberta, Canada, pp. 52-58.

Danilov, I.G., Vitek, N.S., 2012. Chapter 23. Cretaceous trionychids of Asia: an expanded review of their record and biogeography. In: Brinkman, D.B., Holroyd, P.A., Gardner, J.D. (Eds.), Morphology and Evolution of Turtles. Springer, Berlin, pp. 419-438.

Danilov, I.G., Vitek, N.S., 2013. Soft-shelled turtles (Trionychidae) from the Bissekty Formation (Late Cretaceous: late Turonian) of Uzbekistan: Shell-based taxa. Cretaceous Research 41, 55-64.

Ernst, C.H., Barbour, R.W., 1989. Turtles of the World. Smithsonian Institution Press, Washington, D.C.

Fitzinger, L.J.F.J., 1826. Neue Classification der Reptilien nach ihren natürlichen Verwandtschaften (New classification of reptiles according to their natural affinities). J.G. Heubner, Wien (in German).

Gardner, J.D., 1992. Systematics of soft-shelled turtles (family Trionychidae) from the Judith River Formation (Campanian). Unpublished MS thesis, University of Calgary, Calgary, Alberta.

Gardner, J.D., Russell, A.P., Brinkman, D.B., 1995. Systematics and taxonomy of soft-shelled turtles (Family Trionychidae) from the Judith River Group (mid-Campanian) of North America. Canadian Journal of Earth Sciences 32, 631-643.

Gilmore, C.W., 1928. A new species of Aspideretes from the Belly River Cretaceous of Alberta, Canada. Transactions of the Royal Society of Canada 17, 1-10.

Gray, J.E., 1825. A synopsis of the genera of reptiles and Amphibia, with a description of some new species. Annals of Philosophy 10, 193-217.

Gray, J.E., 1831. Synopsis Reptilium; or short descriptions of the species of reptiles, Part I. Cataphracta. Tortoises, crocodiles, and enaliosaurians. Treutel, Wurtz, and Co., London.

Gray, J.E., 1870. Supplement to the catalogue of shield reptiles in the collection of the British Museum. Part I. Testudinata. Taylor and Francis, London.

Hay, O.P., 1904. On the existing genera of the Trionychidae. Proceedings of the American Philosophical Society 42, 268-274.

Hay, O.P., 1905. On the skull of a new trionychid, Conchochelys admiribalis, from the Puerco beds of New Mexico. Bulletin of the American Museum of Natural History $21,335-338$.

Hay, O.P., 1908. The fossil turtles of North America. Carnegie Institution of Washington Publication 75, 1-568.

Hummel, K., 1929. Die fossilen Weichschildkröten (Trionychia). Eine morphologischsystematische und stammesgeschichtliche Studie (The fossil soft-shelled turtles (Trionychia). A morphological-systematic and evolutionary study). Geologische und Palaeontologische Abhandlugen 16, 359-487 (in German).

Hutchison, J.H., 2000. Diversity of Cretaceous turtle faunas of eastern Asia and their contribution to the turtle faunas of North America. Paleontological Society of Korea Special Publication 4, 27-38.

Joyce, W.G., Lyson, T.R., 2011. New material of Gilmoremys lancensis nov. comb. (Testudines: Trionychidae) from the Hell Creek Formation and the diagnosis of plastomenid turtles. Journal of Paleontology 85, 442-459.

Kearney, M., Clark, J.M., 2003. Problems due to missing data in phylogenetic analyses including fossils: a critical review. Journal of Vertebrate Paleontology 23, $263-274$.

Kordikova, E.G., 1994a. Review of fossil trionychid localities in the Soviet Union. Courier Forschungs-Institut Senckenberg 173, 341-358.

Kordikova, E.G., 1994b. About systematics of fossil trionychids in Kazakhstan. Selevina $2,3-8$

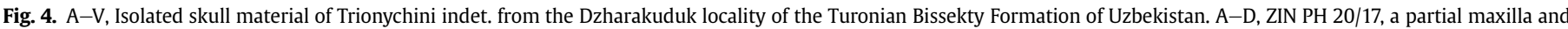

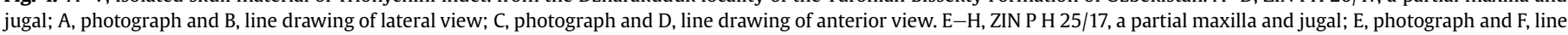

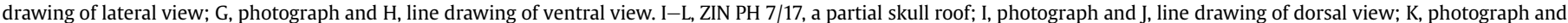

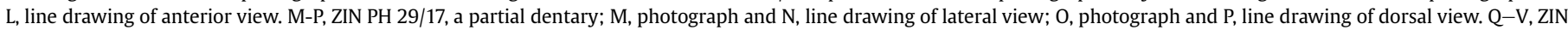

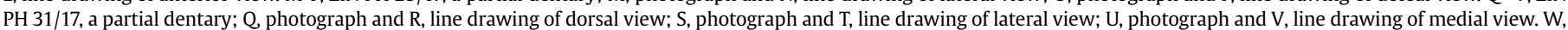

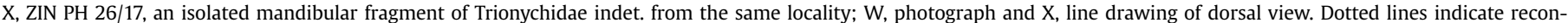

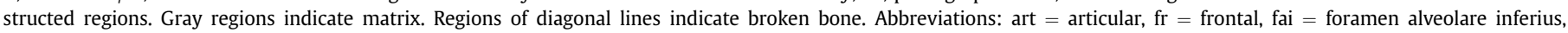
$\mathrm{fdm}=$ foramen dentofaciale majus, $\mathrm{j}=$ jugal, $\mathrm{pa}=$ parietal, $\mathrm{mx}=$ maxilla, sur $=$ surangular. 
Lacépède, B.G.E., 1788. Historie Naturelle des Quadrupèdes Ovipares et des Serpens (A natural history of oviparous quadrupeds and serpents), vol. 1. Hotel de Thou, Paris (in French).

Leidy, J., 1856. Notices of the remains of extinct reptiles and fishes discovered by Dr. F.V. Hayden in the bad lands of the Judith River, Nebraska Territory. Proceedings of the Academy of Natural Sciences of Philadelphia 8, 72-73.

Meylan, P.A., 1987. The phylogenetic relationships of soft shelled turtles (family Trionychidae). Bulletin of the American Museum of Natural History 186, 1-101.

Nessov, L.A., 1986. Some Late Mesozoic and Paleocene turtles of Soviet Middle Asia. Stvdia Geológica Salmanticensia, Volumen Especial 2: Stvdia Palaeocheloniologica 2, 7-22.

Nessov, L.A., 1987. On some Mesozoic turtles of Soviet Union, Mongolia and China, with comments on systematics. Stvdia Geológica Salmanticensia, Volumen Especial 2: Stvdia Palaeocheloniologica 4, 87-102.
Nessov, L.A., 1997. Nemorskie pozvonochnye melovogo perioda Severnoy Evrazii (Cretaceous nonmarine vertebrates of Northern Eurasia). Saint Petersburg State University, Institute of Earth Crust, Saint Petersburg (in Russian).

Ramsay, E.P., 1886. On a new genus and species of fresh water tortoise from the Fly River, New Guinea. Proceedings of the Linnaean Society of New South Wales 1 , $158-162$.

Vitek, N.S., 2012. Giant fossil soft-shelled turtles of North America. Palaeontologia Electronica 15 (1), 1-43.

Vitek, N.S., Danilov, I.G., 2010. New material and a reassessment of soft-shelled turtles (Trionychidae) from the Late Cretaceous of Middle Asia and Kazakhstan. Journal of Vertebrate Paleontology 30, 383-393.

Vitek, N.S., Danilov, I.G., 2012. New data on the soft-shelled turtles from the Upper Cretaceous Kyrkkuduk I locality of Southern Kazakhstan. Proceedings of the Zoological Institute of the Russian Academy of Sciences 316, 50-56. 